\section{$\underset{\substack{\text { hommes } \\ \text { \& migrations }}}{ }$}

\section{Hommes \& migrations}

Revue française de référence sur les dynamiques

migratoires

1293 | 2011

L'immigration dans les musées

\title{
Le goût des nôtres est aussi celui des autres
}

\section{Franck Petit}

\section{OpenEdition \\ Journals}

\section{Édition électronique}

URL : http://journals.openedition.org/hommesmigrations/532

DOI : 10.4000/hommesmigrations.532

ISSN : 2262-3353

\section{Éditeur}

Musée national de l'histoire de l'immigration

\section{Édition imprimée}

Date de publication : 1 septembre 2011

Pagination : 138-141

ISSN : 1142-852X

\section{Référence électronique}

Franck Petit, « Le goût des nôtres est aussi celui des autres », Hommes \& migrations [En ligne], 1293 | 2011, mis en ligne le 29 mai 2013, consulté le 22 septembre 2020. URL : http://

journals.openedition.org/hommesmigrations/532 ; DOI : https://doi.org/10.4000/hommesmigrations. 532

Ce document a été généré automatiquement le 22 septembre 2020.

Tous droits réservés 


\section{Le goût des nôtres est aussi celui des autres}

\section{Franck Petit}

1 Levons avant tout un malentendu entretenu par les médias et par l'État: c'est le rituel du repas à la française, et non la cuisine française, qui a été classé au patrimoine de l'Unesco. Car la gastronomie française, souvent cocardière et parfois appesantie de relents nationalistes, est en soi un concept plus relatif et paradoxalement plus ouvert que le repas cérémoniel, plus aisé à codifier. "Bien sûr que d'autres pays peuvent y accéder [au patrimoine de l'humanité] et je ne suis pas de ceux qui croient que la cuisine française est la meilleure du monde. Et d'ailleurs elle n'existe pas : il faut parler des cuisines françaises", avait voulu préciser Christian Millau ${ }^{1}$, le critique gastronomique co-fondateur du guide Gault et Millau, peu après le dépôt de notre candidature à l'Unesco.

2 "Jadis, ajoutait-il, une journée de cheval vous faisait changer de type de société, de culture, d'habitat, voire de langue, et, bien sûr, de cuisine. Une petite région comme le Rouergue possède quatre cuisines différentes: sud, nord, est, ouest." Et de glisser encore: "Il n'y a rien de commun entre les Bretons du Nord et les Charentais, entre la Picardie et lîle-de-France, entre l'Alsace côté Vosges et le Doubs." Soit, mais la gastronomie française ne serait-elle tout de même pas la "meilleure du monde", comme l'a déclaré le président Nicolas Sarkozy, le 23 février 2008, lors de l'inauguration du Salon de l'agriculture - avant de rabrouer d'un "Casse-toi pauvre con" un paysan réticent à lui tendre la main ? "L'agriculture et les métiers qui la façonnent chaque jour sont à l'origine de la diversité gastronomique de notre pays", avait ajouté le président.

\section{"La cuisine française n'existe pas"}

3 Sous des airs complaisamment provocateurs - "La cuisine française n'existe pas", titrait le magazine Le Point -, Christian Millau n'est cependant pas loin de penser, lui aussi, que nos chefs et nos palais sont les champions du monde. "Pour la cuisine, la France reste bien le centre du monde, poursuit-il. Les cuisiniers de toute la planète sont venus picorer nos idées et les ont utilisées chez eux. Notre Sorbonne gourmande possède de sacrées têtes pensantes qui ont 
nom Guérard, Robuchon, Marx, Roellinger et beaucoup d'autres. Le génie de la France est de savoir absorber les produits d'ailleurs (la fraise comme la pomme de terre) et d'en faire des perles de nos terroirs."

Le génie de la cuisine française serait donc d'“absorber"! Et à y regarder de près, que n'a-t-elle absorbé au fil des siècles. À commencer par le mot "gastronomie" lui-même, vingt-trois siècles après son invention sous la plume gourmande d'un Sicilien. Considéré comme français et décliné comme tel dans de multiples langues, il nous vient du grec gastro ("le ventre") et de nomie ("la loi"). Littéralement, "la loi du ventre". Cependant, rappelle Francis Chevrier', fondateur et directeur de l'Institut européen d'histoire et des cultures de l'alimentation (IEHCA), "la première utilisation de ce mot est issue du traité culinaire d'un lettré grec de Sicile du nom d'Archestrate, ayant vécu au IV siècle avant J.-C. Il y relate un voyage gourmand autour de la Méditerranée. Ce n'est qu'en 1800 qu'il apparaît [en France] dans un long poème intitulé 'La Gastronomie' de Joseph Berchoux, avant d'être popularisé par Brillat-Savarin dans La Physiologie du goût".

\section{Discret hommage aux Russes}

5 "Le repas gastronomique [des Français] doit respecter un schéma bien arrêté, nous dit l'Unesco. Il commence par un apéritif et se termine par un digestif, avec entre les deux au moins quatre plats, à savoir une entrée, du poisson et/ou de la viande avec des légumes, du fromage et un dessert." Mais, comme le souligne toujours Francis Chevrier, dans Notre gastronomie est une culture, cette description évoque une "succession de services", qui se trouve être l'exact opposé de "la manière dont on servait les plats, notamment en France, au début du XIX siècle". À l'époque, poursuit-il, "l'aristocratie française mangeait 'à la française', c'est-à-dire que tous les plats étaient servis en même temps, desserts compris." Et de citer l'historien Frédéric Rouvillois, qui note dans son Histoire de la politesse que ce service "présente d'incontestables inconvénients gastronomiques: en dépit des réchauds, généralement peu efficaces, on arrive le plus souvent à manger froid - y compris les sauces sublimes auxquelles les cuisiniers ont parfois consacré des heures de travail, certaines tendant à se figer, d'autres, qui ne supportent pas de bouillir, risquant de tourner ou de s'aigrir".

6 Ainsi, le repas français tel que l'Unesco le décrit se révèle être un (très discret) hommage... aux Russes. "Les Français n'ont fait que copier la façon d'organiser son repas qu'avait le prince Alexandre Kourakine, ambassadeur de Russie en France de 1808 à 1812", souligne l'écrivain Benjamin Pelletier sur son blog ${ }^{3}$. Ce service "à la russe" s'est imposé dans l'Hexagone au cours du XIXe siècle. Les premiers restaurants ont imité les repas des aristocrates, qui avaient eux-mêmes imité le prince Kourakine. Sans tarder, la bourgeoise le fera sien, puis progressivement l'ensemble de la population française. Jusqu'à sa consécration, deux siècles plus tard, au rang de patrimoine immatériel de l'humanité... tricolore. Comme de nombreux pans de notre culture nationale, ce mode de service n'est ainsi pas français de souche. Il l'est devenu. On l'a absorbé, digéré, intégré. Et ce goût des autres pour un service à l'assiette s'est fait nôtre.

\section{Le mariage de la France et de l'Italie}

7 Une fois cela avalé, il sera peu surprenant d'apprendre que la prestigieuse gastronomie française naît et s'épanouit d'un rendez-vous avec une belle étrangère nommée 
Renaissance. François $1^{\mathrm{er}}$, fasciné, la fait entrer à sa cour. Et c'est cette rencontre de la France et de l'Italie qui serait "déterminante dans le processus d'élaboration de notre gastronomie", écrit encore Francis Chevrier. "C'est sur cette base solide, 'le mariage de la France et de l'Italie, que se produira ensuite l'éclosion de la grande cuisine française au XVII siècle, cuisine qui sera perfectionnée au plus haut point à Versailles, et imitée alors par toute l'Europe aristocratique avant de se diffuser parmi la bourgeoisie, à la suite de la Révolution et au travers d'une invention toute française : le restaurant. Paris deviendra au $\mathrm{XIX}^{\mathrm{e}}$ siècle la capitale gastronomique du monde occidental."

8 Avant elle, la Chine avait développé, rappelle Chevrier, un art de vivre subtil et élégant où la gastronomie avait une place d'honneur. "Une Cour riche et puissante semble un cadre nécessaire pour l'éclosion d'une grande cuisine comme ce fut le cas à Bagdad, à Delhi, à Fès, à Mexico ou encore à Kyoto..." Ce serait donc justice d'ouvrir à d'autres tables, à d'autres coutumes gastronomiques, le champ d'honneur du patrimoine de l'Unesco, comme le souligne le critique culinaire Périco Legasse: "En étant la première à bénéficier de cette haute distinction, la France ouvre la voie à d'autres nations tout aussi méritantes. Le repas des Chinois, le repas des Marocains, le repas des Italiens, le repas des Espagnols, le repas des Turcs méritent eux aussi d'être inscrits un jour au patrimoine de l'humanité. Si la France a ouvert la voie, il est inconcevable qu'elle se croie la seule à l'emprunter. À partir d'aujourd'hui, la gastronomie française n'appartient plus seulement à la France, elle appartient au monde."

\section{“Nationalisme ordinaire"}

9 Tant élégante qu'incantatoire, la formule de Périco Legasse encourage à sortir par le haut, grâce à l'Unesco, d'une hypocrisie d'autant plus criante qu'aujourd'hui la cuisine, comme l'ensemble des activités humaines, n'est plus le résultat d'une absorption mais d'un savant mixage mondialisé. "Passer sous silence l'influence de cultures étrangères sur la culture française revient à ancrer encore plus profondément l'illusion que la culture française serait une création ex nihilo issue du terreau et du terroir de la France et qu'il nous appartiendrait de défendre contre toute intrusion, s'inquiète Benjamin Pelletier. Autrement dit, à force de nous regarder dans le miroir, on en vient à effacer le regard de l'autre; mais aussi son geste, sa parole et, finalement, sa présence et nos interactions sans lesquelles nous ne serions pas ce que nous sommes."

10 Portée par le politique, l'inscription du repas gastronomique des Français au patrimoine de l'Unesco relève pourtant a priori d'une stratégie sans risque majeur pour un pouvoir en quête de ciment fédérateur. Entretenir la fierté du bon goût des nôtres ne pouvant se faire sans rassembler symboliquement ce qu'il contient d'apports des régions et de l'histoire de France, personne n'en est exclu. En théorie. Car “la question de la cuisine 'nationale' renvoie au sein de la société française à un nationalisme ordinaire, c'est-àdire un ensemble de pratiques routinières, d'actions et de valeurs développées par les membres de la communauté nationale pour perpétuer quotidiennement la relation d'identification à la nation, souvent de manière inconsciente, dans un État-nation stable et établi comme la France, analyse Vincent Martigny ${ }^{4}$.

11 À l'étranger, poursuit-il, la gastronomie constitue l'un des marqueurs de la spécificité nationale dans la mondialisation, particulièrement depuis les années quatre-vingt-dix. Elle permet à la France, à travers la valorisation du goût français, d'occuper une place symbolique dominante et illustre la réaction française à une mondialisation réputée 'acculturante' ou 'américanisée'." Le goût des autres n'est donc pas toujours du goût des nôtres. Mais les Français prennent 
plaisir à entretenir cette croyance - pas totalement injustifiée - que le bon goût et l'art de vivre "à la française" plaisent au reste du monde. Sachant que ce goût des nôtres résulte d'absorptions successives des goûts des autres, peut-être est-ce dès lors cette croyance, cette religion, cette passion bien française, qu'il aurait fallu inscrire au patrimoine immatériel de l'humanité?

\section{NOTES}

1. Le Point, 30 octobre 2008, "La cuisine française n'existe pas".

2. Francis Chevrier, Notre gastronomie est une culture, Paris, Bourin, 2011.

3. http://gestion-des-risques-interculturels.com/pays/europe/france/le-repas-gastronomiquefrancais-a-1\%E2\%80\%99unesco-un-hommage-aux-russes/

4. "Le goût des nôtres : gastronomie et sentiment national en France", in Raisons politiques, $\mathrm{n}^{\circ}$ 37, 2010-2011, Presses de Sciences Po.

\section{RÉSUMÉS}

Aujourd'hui, les bobos parisiens achètent leur riz chez les Tamouls du quartier La Chapelle à Paris, lesquels travaillent dans les cuisines des restaurants fréquentés par ces mêmes bobos... Mais ce n'est là qu'un des multiples courants d'air qui font respirer nos cuisines nationales et le fameux "repas gastronomique des Français", inscrit en 2010 au patrimoine immatériel de l'humanité par l'Unesco. 